\title{
A Finite Element Analysis of the Fatigue Behavior and Risk of Failure of Immediate Provisional Implants
}

\author{
María Prados-Privado 1,2,*, Carlos Ivorra ${ }^{2}$, Carlos Martínez-Martínez ${ }^{2}$, \\ Sergio Alexandre Gehrke ${ }^{3}$ (D) José Luis Calvo-Guirado ${ }^{4}$ (D) and Juan Carlos Prados-Frutos 5 \\ 1 Department Continuum Mechanics and Structural Analysis, Higher Polytechnic School, \\ Carlos III University, Avenida de la Universidad 30, 28911 Leganés, Madrid, Spain \\ 2 Research Department, ASISA Dental, Calle José Abascal 32, 28003 Madrid, Spain; \\ carlos.ivorra@asisadental.com (C.I.); carlos.martinez@asisa.es (C.M.-M.) \\ 3 Department of Research, Biotecnos, Cuareim 1483, Montevideo CP 11100, Uruguay; \\ sergio.gehrke@hotmail.com \\ 4 Department of Oral and Implant Surgery, Faculty of Health Sciences, Universidad Católica de \\ Murcia (UCAM), 30107 Murcia, Spain; jlcalvo@ucam.edu \\ 5 Department of Medicine and Surgery, Faculty of Health Sciences, Rey Juan Carlos University, \\ Avenida de Atenas s/n, 28922 Alcorcón, Madrid, Spain; juancarlos.prados@urjc.es \\ * Correspondence: mprados@ing.uc3m.es; Tel.: +34-914-44-30-12
}

Received: 9 April 2019; Accepted: 6 May 2019; Published: 8 May 2019

\begin{abstract}
Background: Temporary dental implants are used to support provisional prostheses. The goal of this study was to obtain the stress-number (S-N) curves of cycles of five temporary dental implants employing finite element methods. Additionally, a probabilistic analysis was carried out to obtain the failure probability of each dental implant. Methods: To obtain these curves, first the maximum value of the fracture load was obtained by simulation of a compression test. Subsequently, the fatigue life was simulated by varying each of the loads from the maximum value to a minimum value (10\% of the maximum value), and the minimum number of cycles that it should support was calculated. Results: The fatigue limit of titanium in these implants was around $200 \mathrm{MPa}$ with the maximum number of cycles between 64,976 and 256,830 . The maximum compression load was between 100 and $80 \mathrm{~N}$. Regarding the probability of failure, all implants were expected to behave similarly. Conclusions: This study of finite elements provided the values of maximum load supported by each of the implants, and the relationship between the stress in the implant and the number of cycles that it could support with a probability of failure. An international standard on how to perform fatigue studies in temporary dental implants was deemed necessary.
\end{abstract}

Keywords: temporary dental implants; fatigue; fracture; titanium alloy; failure probability

\section{Introduction}

Immediate provisional implants (IPI) are medical devices employed temporarily to support a provisional prosthesis for restoring a patient's masticatory and aesthetics function during implant treatment. Provisional or temporary dental implants, which are inserted at the same time as the permanent implants, are used to hold the prosthesis, generally complete, while the permanent dental implants complete the osseointegration. So, a patient can employ a provisional prothesis with these temporary dental implants [1]. Like osseointegrated dental implants, temporary implants are subjected to a dynamic load which act repeatedly on the implant.

There are some differences between provisional and permanent dental implants. One of them is related to the geometry of the implants. Generally, the temporary implants have a connection to the prosthesis in the same body of the implant, while in the permanent implants, there are different components. 
In addition, the diameters of temporary ones are smaller than the permanent ones. Another difference is that temporary implants do not obtain osseointegration, and are withdrawn once the osseointegration has occurred, allowing the definitive prosthesis to be fixed to the definitive osseointegrated implants [2].

The main goal of the IPI is the stabilization of the transitional prosthesis during the period of osseointegration of the permanent implants, so that the endosseous implants can definitively support the designed prosthesis; this helps to avoid load on the implants during the osseointegration process, allowing patients to carry a provisional prosthesis that facilitates the aesthetic and masticatory function.

Usually, the use of the IPI resides in cases in which a variable number of endosseous implants are sequenced in a complete arcade, generally on the mandible, which must be protected from functional load while the osseointegration is being carried out. However, a patient is always advised to retain the provisional prosthesis during the months of osteointegration, which is generally about two to four months, depending on the particular circumstance of the patient and the case.

These immediate provisional implants (IPI) can be used as a provisional implant in agenesis of upper and lower incisors, and to load temporary prostheses of large rehabilitations in clinical use.

A fracture, which is the biggest problem of temporary dental implants, is a common cause of implant failure, and it occurs due to repetitive masticatory load that an implant is exposed to, after being placed in the mouth [3]. However, temporary dental implants are susceptible to failure earlier than permanent dental implants. Some studies suggest that overload is the main cause of failure and fracture of the temporary dental implants [4]. However, the success rate of these kind of treatments has been shown to be over $90 \%$ [5].

The development of dental implants comes with techniques to evaluate their behavior and standards have been established to guarantee their quality [6,7]. The International Organization for Standardization standard 14801 (ISO 14801) addresses the dental implants of the endosseous or the transmucosal type, which is used in many countries. This standard details how the fatigue behavior of dental implants should be evaluated in the most unfavorable clinical conditions [8].

According to this standard, testing a single dental implant takes several days, so it is necessary to employ a large sample size of implants. Therefore, fatigue testing of dental implants is very expensive in terms of both, the testing time and the number of specimens used [9]. Finite element analysis is a good tool to carry out this fatigue analysis and to reduce the cost associated with the in vitro study.

The impact of the randomness of many of the variables that take part in the fatigue behavior testing of the dental implants (both permanent and provisional) make that the results obtained by deterministic tests unreliable. For this reason, probabilistic fatigue studies should be included, because they can measure the variability of the variables $[10,11]$.

The goal of this study was to obtain the stress-number of cycles (S-N) curves of temporary dental implants with five different lengths, employing finite element analysis, to know the fatigue properties, and to obtain the probability of failure associated to each cycle.

\section{Materials and Methods}

\subsection{Study Design}

This is a numerical study to obtain the S-N curves of the IPI implants with five different lengths which are not yet on the market. In order to carry out this study, it was not necessary to obtain an ethical committee or patients.

\subsection{Temporary Dental Implants Analyzed}

This study analyzed five new temporal dental implants manufactured by Bioner S.A. (Madrid, Spain), which are not commercialized. The main difference between these implants lies in the total length and the length of the threaded part. In all of the cases, the diameter of the area where the thread starts is $2 \mathrm{~mm}$ and the maximum diameter is $2.75 \mathrm{~mm}$.

Figure 1 represents the main measurements of the five temporal dental implants. 


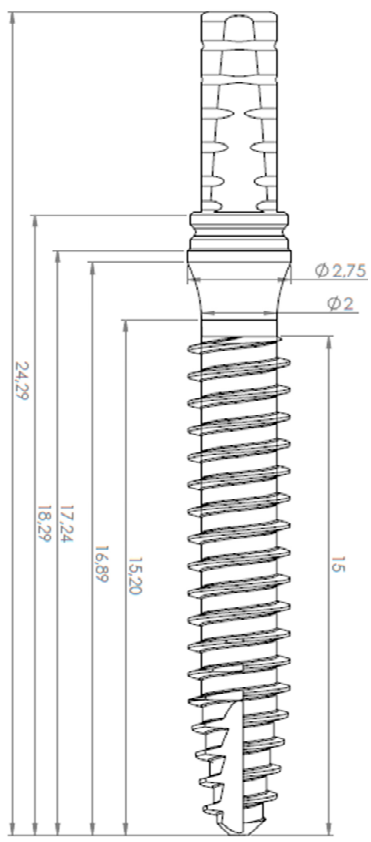

(a)

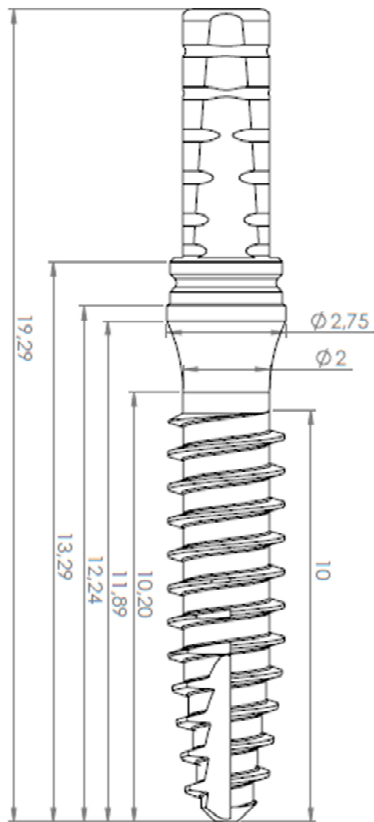

(d)

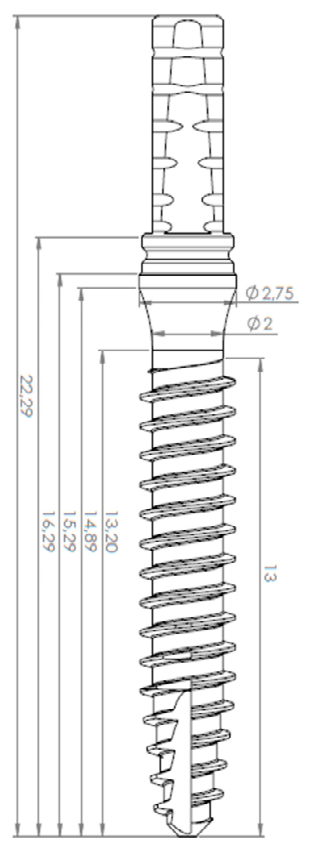

(b)

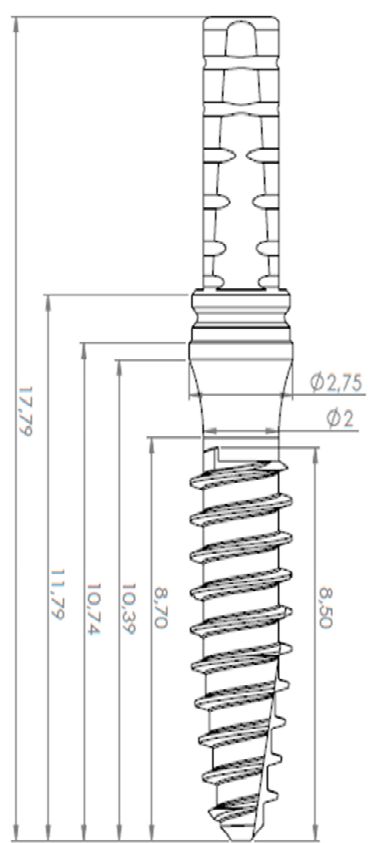

(e)

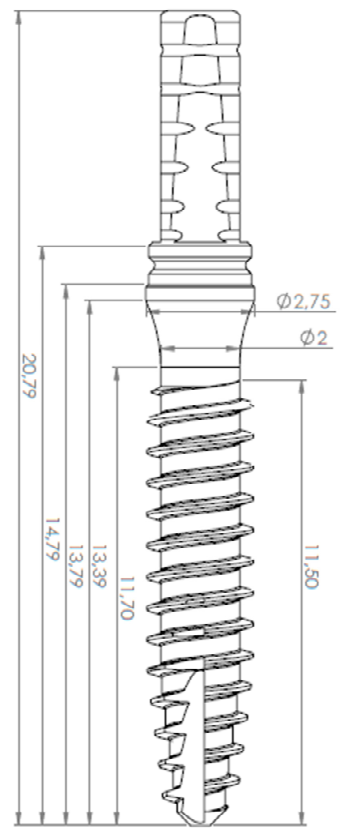

(c)

Figure 1. Temporary dental implants analyzed: (a) length $15 \mathrm{~mm}$; (b) length $13 \mathrm{~mm}$; (c) length $11.5 \mathrm{~mm}$; (d) length $10 \mathrm{~mm}$; (e) length $8.5 \mathrm{~mm}$.

\subsection{Finite Element Model}

Three-dimensional assemblies were created using the commercial software SolidWorks ${ }^{\circledR} 2016$ (Dassault Systèmes, SolidWorks Corp., Concord, MA, USA). All components shown in Figure 2 were manually created except the geometry of dental implants, which were provided by the manufacturer. The geometry of bone and crown were modelled according to the international standard and is detailed in Figure 2.

The assembly shown in Figure 2a is the three-dimensional model which was imported to the ANSYS ${ }^{\circledR}$ Workbench 19.2 (Canonsburg, PA, USA) where the simulation was carried out. 


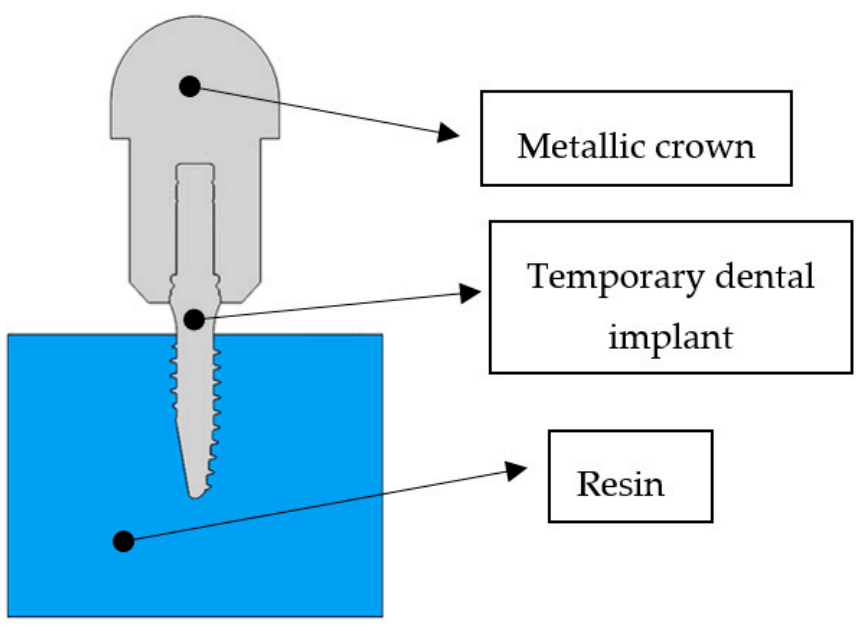

(a)

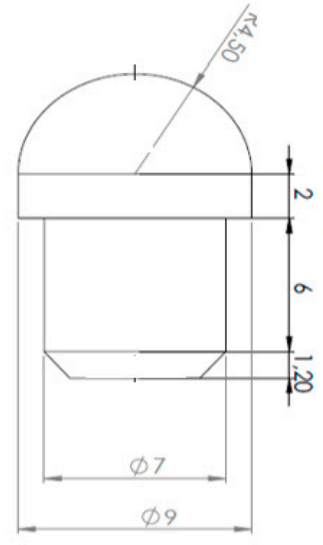

(b)

Figure 2. Components of the assembly. (a) a view of the assembly; (b) crown measures.

Dental implants are composed of titanium alloy. According to the standard ISO 14801:2017, the crown was simulated metallic and the resin was simulated with Young's modulus, similar to cortical bone [8]. Implants, crowns, and bones were modeled with linear, elastic, isotropic, and homogeneous properties. Table 1 details the mechanical properties of materials assigned in this study.

Table 1. Mechanical properties of materials.

\begin{tabular}{ccc}
\hline Material & Young's Modulus (GPa) & Poisson's Ratio (-) \\
\hline Titanium alloy & $100 \pm 20$ & 0.3 \\
Metallic crown [12,13] & 218 & 0.33 \\
Resin [11] & 13.7 & 0.3 \\
\hline
\end{tabular}

All models employed in the present study were constrained as follows: All degrees of freedom in the bottom and lateral surfaces of the resin were restrained. According to ISO 14801:2017, the force was applied with an angle of $30^{\circ}$ with respect to the axis of the implant.

The number of nodes used in this study, from the smallest length to the longest implant length, were: $171,299,296,356,194,324,220,584,256,402$.

\subsection{Compressive Fracture Simulation}

According to the international standard ISO 14801:2017, the compression test has been carried out following the scheme shown in Figure 3.

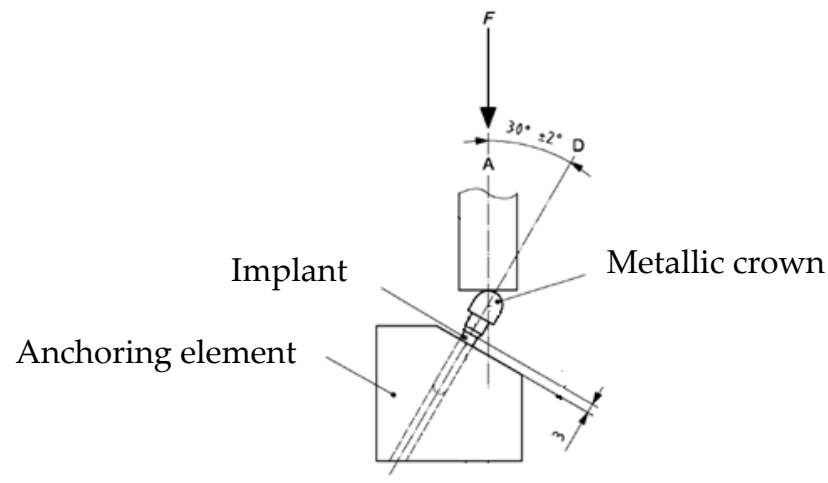

Figure 3. Installation scheme of the assembly. 


\subsection{Fatigue Simulation}

According to the standard, the cyclic loads applied have always oscillated between a maximum value (Pmax) and a minimum (Pmin) value. The value of the load in each of the tests has been obtained by reducing the value of the previous test by $20 \%$. The maximum value obtained was in the compression test and the minimum value was approximately $10 \%$ Pmax. With each load value, a minimum number of life cycles was obtained for each implant.

\subsection{Probabilistic Fatigue}

Physical magnitudes used in previous fatigue analysis were deterministic, but the reality is that these magnitudes are subject to uncertainty. Therefore, using a probabilistic method to study fatigue is justified and useful in the area of dentistry. Young's modulus and Poisson's ratio were considered as random variables. Authors employed the Probabilistic Finite Element Method (PFEM) to obtain the mean and variance of stress and strains, and then obtained the life prediction and the probability of failure using the Bogdanoff and Kozin damage model. The authors referred to Prados-Privado et al. [14] for further details.

The probabilistic methodology applied allowed us to determine the reliability of the provisional dental implants, with a probability of local failure of the implant after a specific number of load cycles.

\section{Results}

\subsection{Compression Test Results}

Each of the implants was subjected to the compression test and the maximum force applied before the fracture was measured. These values are shown in the Table 2.

Table 2. Maximum load obtained.

\begin{tabular}{cc}
\hline Implant & Load [N] \\
\hline Length $15 \mathrm{~mm}$ & 100 \\
Length $13 \mathrm{~mm}$ & 100 \\
Length $11.5 \mathrm{~mm}$ & 100 \\
Length $10 \mathrm{~mm}$ & 50 \\
Length $8.5 \mathrm{~mm}$ & 80 \\
\hline
\end{tabular}

Figure 4 shows the stress distribution in one of the implants, the area where maximum stress appears has been enlarged. This point coincides with the point where the resin ends.
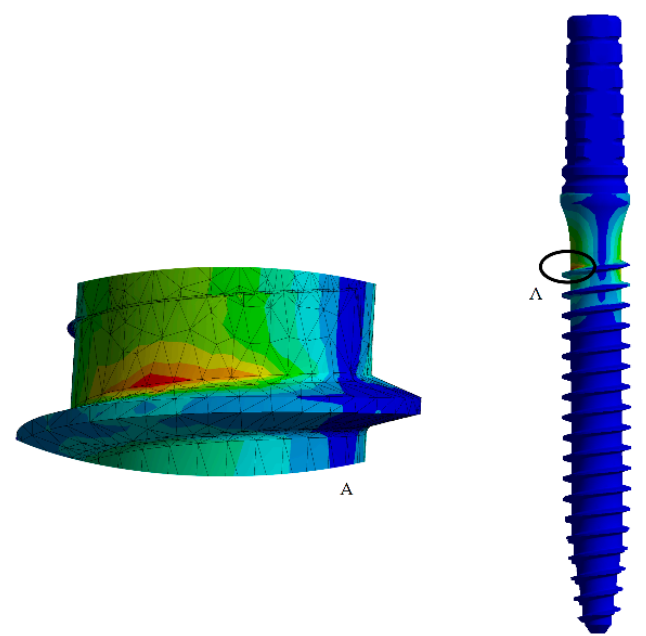

Figure 4. Stress distribution along the implant. 


\subsection{Dynamic Loading Test Results}

Once the greatest load was measured in each temporary dental implant, the fatigue test was carried out. For each of the loads, a minimum value of life cycles was obtained, which were subsequently plotted to obtain the S-N curves associated with each of the implants. The load values and number of cycles obtained during the dynamic simulation are shown in Table 3.

Table 3. Data employed to plot the S-N curves.

\begin{tabular}{|c|c|c|c|c|c|}
\hline \multicolumn{3}{|c|}{ Length $15 \mathrm{~mm}$} & \multicolumn{3}{|c|}{ Length $13 \mathrm{~mm}$} \\
\hline Load [N] & Stress [MPa] & Cycles & Load [N] & Stress $[\mathrm{MPa}]$ & Cycles \\
\hline 100 & 1106 & 122.15 & 100 & 1500 & 81.18 \\
\hline 80 & 1069 & 199.95 & 80 & 1275 & 138 \\
\hline 64 & 785 & 812.38 & 64 & 1020 & 338.67 \\
\hline 51.2 & 542 & 1302 & 51.2 & 816 & 923.72 \\
\hline 40.96 & 456 & 1695 & 40.96 & 653 & 1391 \\
\hline 32.77 & 416.1 & 2135.6 & 32.77 & 522 & 1766 \\
\hline 26.21 & 315.87 & 3060 & 26.21 & 417 & 3029 \\
\hline 20.97 & 300 & 3705 & 20.97 & 417 & 3029 \\
\hline 16.78 & 222.93 & 18,141 & 16.78 & 267 & 9750 \\
\hline 13.42 & 179 & 56,467 & 13.42 & 214 & 19,998 \\
\hline 10.74 & 0 & 94,170 & 10.74 & 171 & 64,976 \\
\hline \multicolumn{3}{|c|}{ Length $11.5 \mathrm{~mm}$} & \multicolumn{3}{|c|}{ Length $10 \mathrm{~mm}$} \\
\hline Load $[N]$ & Stress [MPa] & Cycles & Load [N] & Stress [MPa] & Cycles \\
\hline 100 & 1153 & 175.51 & 50 & 1153 & 199.43 \\
\hline 80 & 922.61 & 619.6 & 40 & 856 & 808 \\
\hline 64 & 738 & 1148.5 & 32 & 685 & 1299 \\
\hline 51.2 & 590 & 1571.6 & 25.6 & 584 & 1692 \\
\hline 40.96 & 472 & 1910 & 20.48 & 438 & 2104.2 \\
\hline 32.77 & 377 & 4819 & 16.38 & 350 & 6029.1 \\
\hline 26.21 & 302.27 & 8200.3 & 13.11 & 280 & 9159.4 \\
\hline 20.97 & 241 & 14,200 & 10.49 & 224.69 & 17,773 \\
\hline 16.78 & 193 & 41,561 & 8.39 & 179.97 & 56,096 \\
\hline 13.42 & 154.77 & 82,350 & 6.71 & 143 & 93,975 \\
\hline 10.74 & 123 & $1.59 \times 10^{5}$ & 5.37 & 115,02 & $1.96 \times 10^{5}$ \\
\hline \multicolumn{3}{|c|}{ Length $8.5 \mathrm{~mm}$} & & & \\
\hline Load [N] & Stress [MPa] & Cycles & & & \\
\hline 80 & 1043 & 273.64 & & & \\
\hline 64 & 834.65 & 871.71 & & & \\
\hline 51.2 & 667.72 & 1350.2 & & & \\
\hline 40.96 & 534.71 & 1732.9 & & & \\
\hline 32.77 & 427.37 & 2609.4 & & & \\
\hline 26.21 & 341.85 & 6432.9 & & & \\
\hline 20.97 & 273.48 & 9487.1 & & & \\
\hline 16.78 & 218.83 & 18,993 & & & \\
\hline 13.42 & 178.93 & 56,919 & & & \\
\hline 10.74 & 134.06 & 97,827 & & & \\
\hline 8.59 & 112.03 & 256,830 & & & \\
\hline
\end{tabular}

From the data in Table 3, it is possible to obtain the S-N curves associated with each of the implants. Figure 5 shows these curves, where a fairly similar behavior is seen between temporary implants of different lengths. 


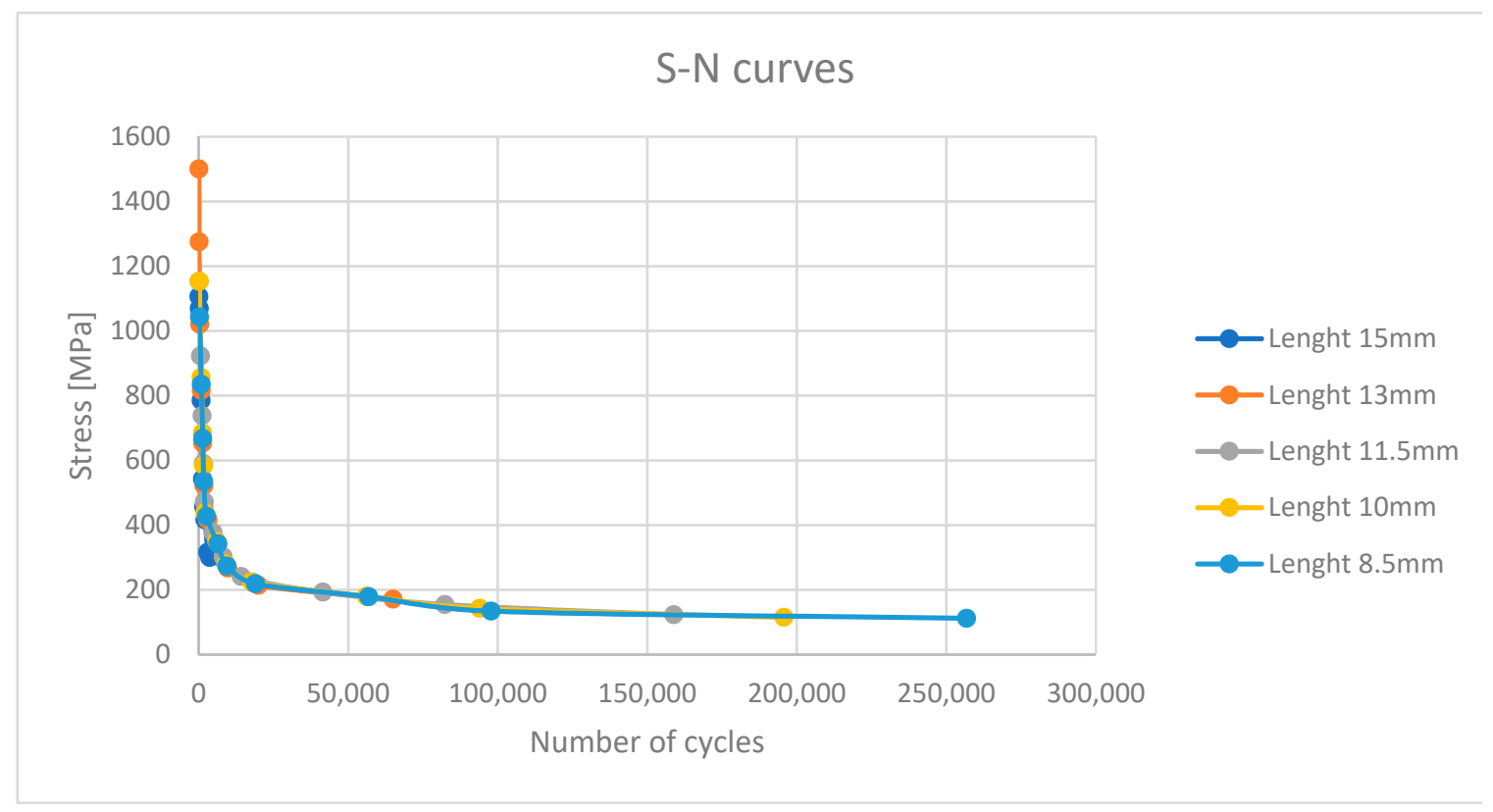

Figure 5. S-N curves obtained from the results of Table 2.

\subsection{Probabilistic Fatigue}

The probabilistic approach was carried out after the fatigue analysis was finished with the aim of obtaining a better characterization of the new provisional dental implants (IPI). The elasticity modulus of titanium was chosen as a random variable with a value of $100 \pm 20 \mathrm{GPa}$.

The mathematical model constructed the cumulative probability functions details in Figure 6. This figure relates the probability of failure with the number of load cycles. According to this figure, the temporary dental implants should have a similar behavior.

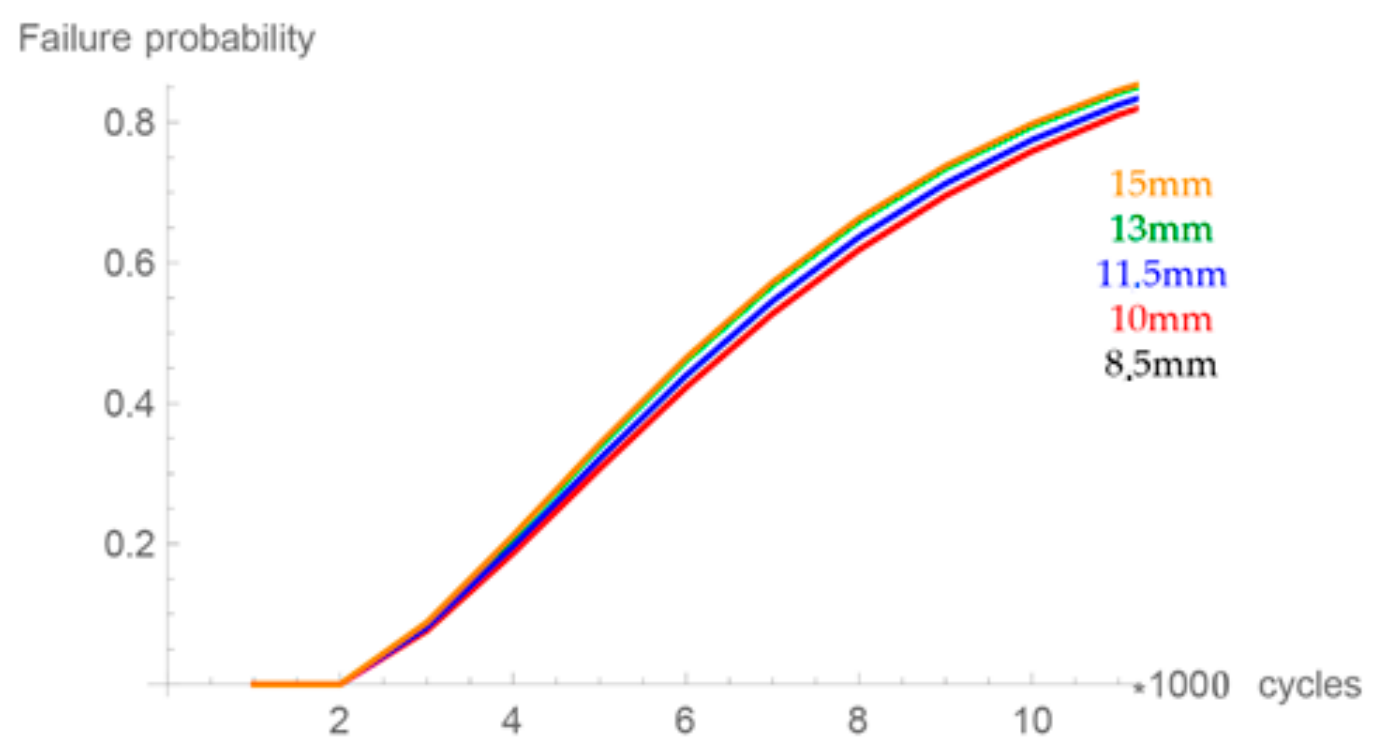

Figure 6. Graphs that relate the probability of failure with the number of cycles.

\section{Discussion}

The aim of this study was to obtain the stress-number (S-N) curves of cycles of five temporary dental implants and the relation between the probability of failure and the number of load cycles. S-N curves summarized the fatigue properties of each of the provisional dental implants (IPI), relating for each stress 
value the number of cycles it resisted, and the time it took to fail. To obtain these curves, a compression simulation was first performed to calculate the maximum load that the implant was able to withstand.

Once the assembly was imported into the finite element software, it was meshed, taking into account that a good finite element mesh was crucial because of the stress singularities expected at the sharp corners. The goal of the compression test was to obtain the maximum load value that the implant was capable of supporting until a fracture occurred. This value would be used later in the dynamic test of fatigue behavior.

Once this maximum load value was known, all the force values for which the dynamic simulation was to be made were calculated. That range of values was from the maximum load to a minimum value of approximately $10 \%$ of said force. Then a dynamic simulation was performed for each force within the range in order to obtain the number of cycles that would be able to withstand those conditions. Both the compression and the fatigue tests were carried out following the requirements detailed in the standard ISO 14801:2017 [8].

Finally, a probabilistic model was computed to measure the variability of some of the variables with the goal to obtain the relation between the failure probability and the number of cycles.

The important feature of this study was that, as Kim et al. detailed in [1], fracture was the biggest problem of temporary dental implants. However, this study had certain limitations. One of these limitations was that there was no standard for the fatigue of temporary dental implants. The use of the ISO 14801:2017 standard to analyze temporary implants was supported by the literature [1], however a specific method for this type of implants would be necessary. Other limitations were related to the properties of the material. The properties of the metallic crown were obtained from other scientific studies and the resin, where the implants were immersed, was modeled with linear, elastic, isotropic, and homogeneous properties. These assumptions were accepted and verified by several studies [12,15].

It must be considered that this type of implant was not used for individual crowns but to support complete prostheses, and more rarely, to support fixed prostheses and other parts.

Table 2 shows the maximum load obtained for each implant after the compression loading test and Figure 5 shows the number of cycles associated with each load. The results obtained in this study, both in terms of load and number of cycles, were lower than those detailed in other studies in the literature [1]. This difference may be firstly because of the limitations indicated above, and secondly, due to the geometric differences of the temporary implants used in the studies.

Figure 6 shows the probability of failure with the number of load cycles. These results were lower than the results obtained by the permanent dental implants [11,12].

\section{Conclusions}

To the authors' best knowledge there were no studies in the literature obtaining the S-N curves of temporary dental implants for fatigue behavior through finite elements. To date, only scientific in vivo studies were available, but no one analyzed temporary dental implants from mechanical point of view. Therefore, more studies in this field and an international standard on how to perform fatigue studies in temporary dental implants were deemed necessary.

Our study obtained a fatigue limit of around $200 \mathrm{MPa}$ for all implants with a maximum number of cycles between 64,976 and 256,830. This study of finite elements has provided the values of maximum load supported by each of the implants, which were between 100 and $80 \mathrm{~N}$.

Future work would be to analyze the fatigue behavior of these implants with in vitro tests as well as the behavior of the prosthesis in real situations.

Author Contributions: M.P.-P. conceived, designed and performed the analyses, evaluated the results and wrote part of the paper. C.I. provided critical analysis and reviewed the literature. C.M.-M. provided critical analysis. J.L.C.-G. analyzed the data and evaluated the results. S.A.G. provided critical analysis and wrote part of the paper. J.C.P.-F. conceived the study, provided critical analysis, interpreted the data, and reviewed the literature and the manuscript.

Funding: This research received no external funding. 
Acknowledgments: To Bioner S.A. for providing the geometry of the provisional dental implants.

Conflicts of Interest: The authors declare no conflict of interest.

\section{References}

1. Kim, M.; Cho, E.; Lee, J.; Kim, E.; Yoo, S.; Park, C. Study on Setting of the Fatigue Limit of Temporary Dental Implants. In Proceedings of the 2017 39th Annual International Conference of the IEEE Engineering in Medicine and Biology Society (EMBC), Seogwipo, Korea, 11-15 July 2017; pp. 1962-1965.

2. Misch, C.E. Contemporary Implantology, 3rd ed.; Elsevier Mosby: Maryland Heights, MO, USA, 2009.

3. Ohkubo, C.; Kobayashi, M.; Suzuki, Y.; Sato, J.; Hosoi, T.; Kurtz, K.S. Evaluation of transitional implant stabilized overdentures: A case series report. J. Oral Rehabil. 2006, 33, 416-422. [CrossRef] [PubMed]

4. Grassi, R.; Rebaudi, A.; Trisi, P.; Covani, U.; Barone, A. Bone loss around immediately loaded transitional implants: histologic and microcomputed tomographic analysis-A case report. Int. J. Periodontics Restor. Dent. 2012, 32, e195-e203.

5. Santosa, R. Provisional restoration options in implant dentistry. Aust. Dent. J. 2007, 52, 234-242. [CrossRef] [PubMed]

6. De la Rosa Castolo, G.; Guevara Perez, S.V.; Arnoux, P.-J.; Badih, L.; Bonnet, F.; Behr, M. Mechanical strength and fracture point of a dental implant under certification conditions: A numerical approach by finite element analysis. J. Prosthet. Dent. 2018, 119, 611-619. [CrossRef] [PubMed]

7. Barry, M.; Kennedy, D.; Keating, K.; Schauperl, Z. Design of dynamic test equipment for the testing of dental implants. Mater. Des. 2005, 26, 209-216. [CrossRef]

8. ISO 14801 Dentistry —Implants_Dynamic Fatigue Test for Endosseous Dental Implants; ISO: Geneva, Switzerland, 2017.

9. Duan, Y.; Gonzalez, J.A.; Kulkarni, P.A.; Nagy, W.W.; Griggs, J.A. Fatigue lifetime prediction of a reduced-diameter dental implant system: Numerical and experimental study. Dent. Mater. 2018, 34, 1299-1309. [CrossRef] [PubMed]

10. Jung, R.E.; Pjetursson, B.E.; Glauser, R.; Zembic, A.; Zwahlen, M.; Lang, N.P. A systematic review of the 5-year survival and complication rates of implant-supported single crowns. Clin. Oral Implants Res. 2008, 19, 119-130. [CrossRef] [PubMed]

11. Prados-Privado, M.; Gehrke, S.; Rojo, R.; Prados-Frutos, J. Probability of Failure of Internal Hexagon and Morse Taper Implants with Different Bone Levels: A Mechanical Test and Probabilistic Fatigue. Int. J. Oral Maxillofac. Implants 2018, 33, 1266-1273. [CrossRef] [PubMed]

12. Prados-Privado, M.; Gehrke, S.A.; Rojo, R.; Prados-Frutos, J.C. Complete mechanical characterization of an external hexagonal implant connection: in vitro study, 3D FEM, and probabilistic fatigue. Med. Biol. Eng. Comput. 2018, 56, 2233-2244. [CrossRef] [PubMed]

13. Yamaguchi, K.; Ishiura, Y.; Tanaka, S.; Baba, K. Influence of the Rigidity of a Provisional Restoration Supported on Four Immediately Loaded Implants in the Edentulous Maxilla on Biomechanical Bone-Implant Interactions Under Simulated Bruxism Conditions: A Three-Dimensional Finite Element Analysis. Int. J. Prosthodont. 2014, 27, 442-450. [CrossRef] [PubMed]

14. Prados-Privado, M.; Prados-Frutos, J.C.; Calvo-Guirado, J.L.; Bea, J.A. A random fatigue of mechanize titanium abutment studied with Markoff chain and stochastic finite element formulation. Comput. Methods Biomech. Biomed. Eng. 2016, 19, 1583-1591. [CrossRef] [PubMed]

15. Pérez, M.A.; Prados-Frutos, J.C.; Bea, J.A.; Doblaré, M. Stress transfer properties of different commercial dental implants: a finite element study. Comput. Methods Biomech. Biomed. Eng. 2012, 15, 263-273. [CrossRef] [PubMed]

(C) 2019 by the authors. Licensee MDPI, Basel, Switzerland. This article is an open access article distributed under the terms and conditions of the Creative Commons Attribution (CC BY) license (http://creativecommons.org/licenses/by/4.0/). 